Int. J. Curr. Res. Med. Sci. (2017). 3(7): 66-69

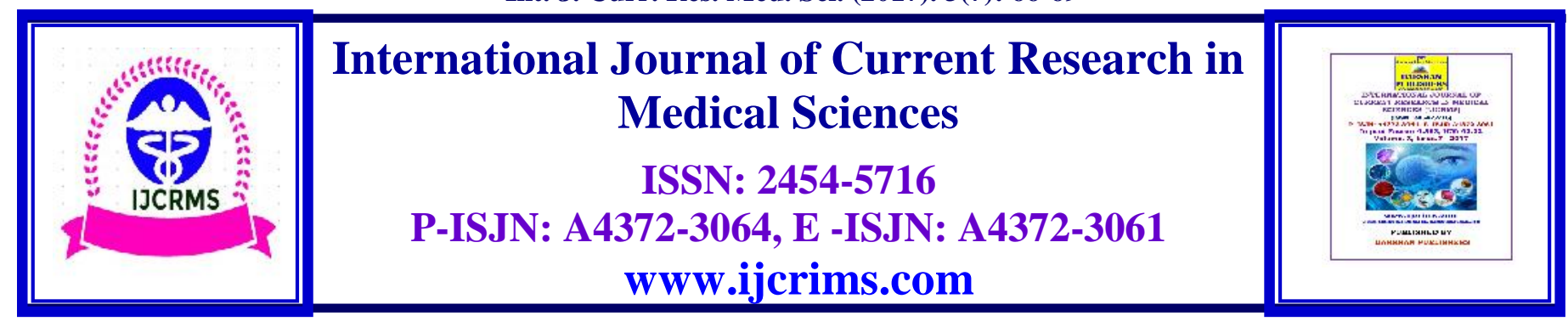

\title{
Standard Operative Procedure on Pugai (Fumigation) in Siddha system of medicine
}

\author{
S.Mohamed Ajmal ${ }^{1}$, M.Naga lakshmi ${ }^{1}$, M.Nandhini ${ }^{1}$, G.Meenadharshini ${ }^{1}$, \\ P.J.Kowshika shree ${ }^{1}$, T.Keerthiga ${ }^{1}$, A.P.Uma ${ }^{2}$. \\ ${ }^{1}$ Final BSMS, Sivaraj Siddha Medical College, Salem-636307.mohamedajmal955@gmail.com, \\ nagalakshmimuthumalai@gmail.com. \\ ${ }^{2}$ Department of Sirappu maruthuvam, Sivaraj Siddha Medical College, Salem-636307. \\ ap_uma@yahoo.in
}

\begin{abstract}
"Pugai (Fumigation)" is one among the external therapy treatment available in Siddha system of medicine. It is the best procedure employed for disinfection and sterilization methodology for the treatment of various diseases. It is usually prepared from herbal products, minerals and animal by-products. This paper gives an overview of Standard Operative Procedure on 'Pugai' and methods of its application
\end{abstract}

Keywords: Pugai, disinfection, herbal products .

\section{Introduction}

Pugai denotes the artificial impregnation of the atmosphere, with the fumes or the smoke of any vegetable or aromatic substances. According to Theraiyar Tharu, Pugai is placed in eighth place at external therapy series. It is the best procedure employed for disinfection and sterilization methodology for the treatment of sinusitis, constricted respiratory pathways, chronic ulcers, tooth ache, head ache, dysmenorrhoea, ano-rectal diseases, dental cavity, fever, arthritis, halitosis, dandruff, and few chronic skin diseases ${ }^{(1,2)}$.

\section{Materials and Methods}

\section{(A) Materials}

For crushing the crude drugs stone mortar and pestle, and for crushing steel mortar and rod, stove or oven, knife, wood and steel spoons, match box, tray, oil lamp or candle are used for the preparation of drugs. For administration a screen for privacy, a set of clothes, wet cloth, a tray with cloves, gauze, cotton role, spirit, castor oil, gingelly oil, tissue paper and separate rooms for men and women. 
(B)

\section{Method 1}

Herbs in the form of juice (or) paste are placed over a piece of cloth. The cloth is rolled as stick and it is allowed to burn. The smoke coming from this wick is subjected to be inhaled by the patient through nose and exhale by mouth. If they inhale through mouth and exhale by nose it will cause head related diseases ${ }^{(1)}$.

\section{(C) Method 2}

In this method, we have to collect the needed herbals in a vessel and allow it to burn in that vessel using a burner. The fume coming from the burnt herbals are used to sterilize the place ${ }^{(1)}$.

\section{(D) Therapeutic source}

Plant parts like pepper, cumin, turmeric, sandal wood, neembark or vegetable oils like castor oil, neem oil, or aromatic substances like sambirani (Styrax benzoin), kukil (Shorea robusta) or animal slough, egg shell, pearl, conch shell, feathers, horns and nails and few prepared medicines like Vidakuzhambu, Agasthiyar kuzhambu, Kousigar kuzhambu. Fumigation controls the infection upto the deeper area of the organs $^{(1)}$.

\section{(E) Eligible criteria}

Fumigation with toxic substances is not advised in newborn, infants, pregnant and lactating women, people under influence of alcohol, suffering from head injury or lock jaw or extreme dryness, eye diseases, anaemia, bleeding disorders, gonorrhoea $^{(3)}$.

\section{(F) Procedure}

For preparation, purify the required drugs and crush the drugs into powder to make a smoke. Fill the smoke tube with powder and smoke pipe is fired at one end. For administration assemble all the articles at the room beside and ask the patient to drink the water before starting treatment. Procedure should be explained to the patient. Patient may be performed either in prone, supine or lateral positions and screen them for privacy.
Except the affected areas all other areas should be covered with a cloth. Gently wash the site and clean dry with sterile cloth. The eliminated fumes should be inhaled 3 or 4 times through mouth and exhaled through mouth not by the nostrils. If exhaled through nostrils it will develop few eye diseases. For skin diseases, piles, fistula, ulcerated wound, the fume released from the smoke pipe is allowed to apply on the affected part or skin. For ano-rectal and vaginal diseases the patient is performed to sit on a stool which has an opening in the top and the drugs are allowed to burn below the stool and the fumes are exposed to the affected part. For the removal wipe the fumigated area with a cloth, gargle the mouth with water or with some herbal decoction if inhaled through mouth. After the procedure dispose the clothing used, then clean the table with soap or antiseptic solution, wash your hands with salt water and leave the patient comfortable. Duration of these treatment was 10-15 minutes for 7 days.

\section{(G) End of proper therapy}

The patient should feel light in head, chest and throat region. The sputum is properly expelled and no congestion is felt ${ }^{(1)}$.

\section{(H) Indications}

Sinusitis, Bronchitis, Ear diseases, Piles, Fistula, Chronic non healing ulcers, Poisonous bites ${ }^{(1,2,3)}$.

\section{(I) Do's and Don'ts for fumigaton}

Inhalation by nostrils is recommended in eye and nasal diseases, while for diseases of the oral cavity, dental caries and jaw, fumes are taken in by mouth but should not be pumped into the lungs. Fumigation when done with mercuriyals, arsenic compounds and blue vitrol-fumigation is done twice a day for three days and once on the fourth day. Fumigation should not be done in empty stomach and the patient should be advised to have cooked rice with milk or butter milk when fumigation is to be done with inorganic substances. Curd is to be avoided. The dietary restrictions includes avoiding sour food like tamarind, salt and spicy foods. Ascertain the 
abstinence of three days before or after the treatment of seven consecutive fumigations. Oil bath with application of Ajowan (omam) paste on the vertex is suggested after the treatment period $^{(1)}$.

\section{(J)Easily available fumigation for Various Diseases}

\section{Fumigation for fistula in ano}

Pig's dung is added to a burning charcoal and exposed to emanating fumes. Agasthiyar kuzhambu pugai is also used for fistula in ano ${ }^{(3)}$.

\section{Fumigation for corn(clarus)}

Fruit of Solanum xanthocarpum (Kandankathiri) is dried and added to burning charcoal and exposed to emanating fumes ${ }^{(4)}$.

\section{Fumigation for headache}

Roll the powder of dried Zingiber officinale (sukku) (100 parts) and Camphor (karpooram) ( 1 part) in a cloth and made into a cigar and lit. The patient suffering from headache is advised to smoke the cigar via nostrils ${ }^{(3)}$.

\section{Fumigation for sinusitis}

Equal amount of purified Lingam (cinnabar) and Thaalagam (yellow orpiment) are made into paste by grinding it with Datura metal (oomathai) leaves extract and Acalypha indica (kuppaimeni) leaves extract respectively. The paste is applied on a cloth and dried. The cloth is rolled like a cigar and lit. The patient suffering from sinusitis is advised to smoke the cigar via nostrils ${ }^{(3) .}$

\section{Fumigation for delirium in children}

Grind equal quantity of Shorea robusta (Kukil), Aquilaria agallocha (Agil), Nigella sativa (Karunjeeragam), Styrax benzoin (Sambirani) and make into a wick and used for fume inhalation. Then Trianthema decandra (Satthisaaranai) and Cleome viscosa (Nalvelai) is fumigated in the same way and fumes are inhaled to get rid of delirium $^{(5)}$.

\section{Fumigation for tooth infections}

Grind equal amount of Trianthema decandra (Satthisaaranai), Calotropis gigantea (Erukku), Santalum album (Sandhanam), Styrax benzoin (Sambirani), Acorus calamus (Vasambu), Zingiber officinale (sukku), Lingam (Cinnabar) are added to burning charcoal and exposed to emanating fumes. Before fumigation apply Neem oil in the affected site ${ }^{(3)}$.

\section{Fumigation for hiccough}

Roll the powders of Santalum album (sandhnam) and Styrax benzoin (Sambirani) in a paper and make it into a cigar. The patient suffering from hiccough advised to smoke the cigar ${ }^{(6)}$.

Table 1. Traditional medicines used as fumigant ${ }^{(3)}$.

\begin{tabular}{|l|l|l|}
\hline S.No & \multicolumn{1}{|c|}{ Diseases } & \multicolumn{1}{|c|}{ Fumigant(Pugai) } \\
\hline 1. & Respiratory diseases & Oomathai poo pugai(Datura metal) \\
\hline 2. & Syncope & Agasthiyar kuzhambu pugai \\
\hline 3. & Childhood epilepsy & Kuthirai kuzhambu pugai \\
\hline 4. & Sinusitis & Sukku thiri pugai \\
\hline 5. & Headache & Sambirani pugai \\
\hline 6. & Nasal congestion & Agasthiyar kuzhambu pugai \\
\hline 7. & Dental caries & Kandankathiri pugai \\
\hline 8. & Non healing ulcers & Virana thoobam \\
\hline
\end{tabular}




\section{Discussion}

The process during therapy cleans the surface impurities from microbes, protects the topical skin from toxins. Possesses anti septic, analgesic and anti inflammatory activities. Increases the peripheral circulation.

\section{Conclusion}

The speciality of fumigation lies in both prophylactic and therapeutic in nature. Also used for effective sterilization purpose. This Standard Operative Procedure defines the use of therapeutic Pugai for various diseases and serves as a Stand-alone product.

\section{References}

1. Dr.T.Thirunarayanan, External therapies of siddha medicine, $1^{\text {st }}$ edition, 2010, p.no. 106, 107, 108.

2. Dr.J.Jayavenkatesh, Agam puram $64,1^{\text {st }}$ edition, 2014, p.no. 190.

3. Dr.Utthamarayan, Siddhar aruvai maruthuvam, $6^{\text {th }}$ edition, 2013 , p.no. 40,82 , 174, 184.

4. Dr.R.Thiyagarajan, Special medicines in siddha, $1^{\text {st }}$ edition, 2009, p.no. 229.

5. Murugesa mudaliyar, Kuzhandai maruthuvam, $5^{\text {th }}$ edition, 2016, p.no. 108.

6. R.C.Mohan, Pulipaani-500, $2^{\text {nd }}$ edition, 2013, p.no. 30 .

\begin{tabular}{|c|c|}
\hline \multicolumn{2}{|c|}{ Access this Article in Online } \\
\hline 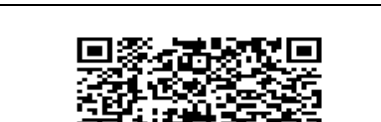 & $\begin{array}{l}\text { Website: } \\
\text { www.ijcrims.com }\end{array}$ \\
\hline 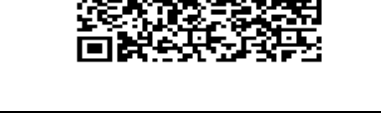 & \multirow[t]{2}{*}{$\begin{array}{l}\text { Subject: } \\
\text { Siddha Medicine }\end{array}$} \\
\hline Quick Response Code & \\
\hline
\end{tabular}

How to cite this article:

S.Mohamed Ajmal, M.Naga lakshmi, M.Nandhini, G.Meenadharshini, P.J.Kowshika shree, T.Keerthiga, A.P.Uma. (2017). Standard Operative Procedure on Pugai (Fumigation) in Siddha system of medicine. Int. J. Curr. Res. Med. Sci. 3(7): 66-69.

DOI: http://dx.doi.org/10.22192/ijcrms.2017.03.07.011 